\title{
Microstructure and Relative Humidity Effects on Long-Term Indentation Creep Properties of Calcium Carbonate Cement
}

\author{
Jesús Rodríguez-Sánchez ${ }^{1 * *}$, Qing Zhang ${ }^{2}$ and Dag Kristian Dysthe${ }^{1}$. \\ 1. Physics of Geological Processes (PGP), The NJORD Centre, Department of Physics, University of Oslo, PO \\ Box 1048 Blindern, Oslo, Norway. \\ 2. Lafarge Centre de Recherche, 95 rue du Montmurier, BP 1538291 St Quentin Fallavier Cedex, France. \\ *E-mail: j.r.sanchez@,fys.uio.no
}

\begin{abstract}
This paper addresses the effect of both microstructure and relative humidity on the long-term creep properties of sustainable calcium carbonate $\left(\mathrm{CaCO}_{3}\right)$ cements. Those can be prepared by mixing amorphous calcium carbonate and vaterite with water. A larger starting amount of vaterite, $X_{V}$, within the mixture design gives a higher elasticity and resistance to the specimens due to the larger overall bridging area within the newly formed calcite crystals. Regarding creep properties for a given relative humidity, the amplitude of creep strain decreases with $X_{V}$, and makes the relation between the elastic modulus, E, and hardness, $H$, of the samples to be linear with the contact creep modulus, $C$. On the other hand, for a given composition, the amplitude of creep increases with the relative humidity, making the contact creep modulus, $C i$, to rise exponentially with the elastic modulus, $E$, and hardness, $H$, of the specimens. The most probable creep mechanisms for this kind of cement seem to be a combination of microcraking in the early stages and dissolution and reprecipitation of calcite in the long-term (also known as pressure solution theory). The presence of water in pores with increasing relative humidity might enhance the local dissolution of calcite, and hence the creep amplitude.
\end{abstract}

Keywords: calcium carbonate cement; compressive strength; creep; $\mu$-indentation; microstructure; relative humidity.

\section{Introduction}

Due to the carbon footprint of ordinary Portland cement (OPC) there has been an increased interest in alternative hydraulic binders [1-4]. Among natural cements; one of the most common is calcium carbonate $\left(\mathrm{CaCO}_{3}\right)$ but despite of its abundance; very few attempts have reported its usage as an artificial cementing agent for engineering purposes. Among the first ones; the method originally proposed by Cailleau [5] and later modified by Molenaar \& Venmans [6] proposed the recirculation of $\mathrm{Ca}(\mathrm{OH})_{2}$ solution; pumped by $\mathrm{CO}_{2}$; through the sample aiming to cement. As the solution pass through the sample; $\mathrm{CaCO}_{3}$ encounter suitable nucleating sites among the host grains and work as a bonding agent. A commercially version of this methodology was tested by Ismail et al. [7] with different soils including glass beads; calcareous sand and 
silica sand. However; all these approaches require soil casting under sealed conditions to flush the starting solutions; making them absolutely unpractical to apply on site in comparison with a paste option.

Alternative production paths to form calcium carbonate binders has been investigated $[1 ; 8 ; 9]$. The first $\mathrm{CaCO}_{3}$ cement pastes; with similar mouldable and malleable properties as ordinary Portland cement (OPC) pastes were synthesized by Fontaine et al. [8] and Combes et al. [9]. They mixed water with two $\mathrm{CaCO}_{3}$ solid phases: one was the highly reactive amorphous calcium carbonate; ACC; while the other was one of the metastable crystalline phases; either vaterite; V; or aragonite; Ar; which acted as a seed for their (re)crystallization into the most stable calcite polymorph during the setting reaction.

Due to environmental benefits of $\mathrm{CaCO}_{3}$ cement; i.e. no $\mathrm{CO}_{2}$ production; low energetic costs; etc.; in comparison with OPC; we aim at further characterizing and analysing its mechanical properties; especially the compressive strength and creep deformation; before considering a commercial upgrade.

Undoubtedly; the compressive strength is the most relevant property that engineers and architects needs to know to design and calculate structures built on this material. Combes et al. [9] reported values within 3-13 $\mathrm{MPa}$ for $\mathrm{CaCO}_{3}$ pastes with diverse microstructures; but the effect of the mixture design on the mechanical properties still requires further understanding.

Another property that demands significant analysis before up-grading $\mathrm{CaCO}_{3}$ cements to commercial production is its long term deformation. Since the classical experiments of Phillips [10] and Andrade [11]; considerable interest has been given to creep deformation; which stands for slow deformation of materials at constant stress conditions with respect to time. Moreover; the importance of taking creep deformation into consideration in the design of structures was recalled recently since it may cause deflection and curvature; cracking and redistribution of stresses [12;13]. Creep in polycrystalline aggregates such as $\mathrm{CaCO}_{3}$ cement usually evolves through three stages: an initial transient phase with decelerating strain rate; a second steady state creep and a final accelerating creep phase [14]. Several models have been proposed to describe the behaviour for the three of them [15-17] although most either ignore the underlying microstructural phenomena of the creep mechanism or set aside the effect of dissolution which is usually coupled with compaction creep. Keszthelyi et al. [18]; however; presented a novel micromechanical approach to describe transient creep of rocks with fluid-filled porous by combining fracturing and pressure solution. Nevertheless; creep of cementitious materials is a complex issue and it is still difficult to predict in the long-term since it is often coupled with other phenomena such as hydration and drying; while it can be influenced by several parameters such as temperature; seasonal moisture changes; level of stress; water content and mixture design simultaneously.

Since cementitious materials are multi-scale porous materials; creep is largely influenced by the presence of water in porosity and therefore by moisture changes. Multiple studies have already pointed out the necessity of controlling the moisture equilibrium of the samples before creep evaluation. For instance; Pickett [19] found that ordinary concrete under load and being dried at same time presented a higher deformation than that of a sample under load without drying. Moreover; Tamtsia and Beaudoin [20] found that the history of 
drying also influence the basic creep of cement pastes. The amplitude of creep was lower for those samples which set without drying. As a consequence; radically different interpretations of experimental data; and therefore theories; have been proposed to rationalize creep of cementitious materials [21-24]. Although most authors agree to point out that the origin of long-term creep in OPC lies in the amorphous calcium-silicatehydrate (C-S-H) phase [25;26]; we aim at unravelling the mechanisms for pure crystalline carbonate systems without this amorphous phase and at comparing the results with state-of-the-art creep models [18].

In the present study; free- $\mathrm{CO}_{2} ; 100 \%$ pure calcium carbonate cements have been synthesized at laboratory scale following Combes method [9] as a proxy to investigate the effect of both microstructure and moisture on long-term basic creep behaviour of pure calcium carbonate materials. The effect of microstructure is studied by preparing and testing samples with varied mixture design while the effect of moisture is studied by conditioning and testing those compositions in various relative humidity $(\mathrm{RH})$ conditions. Creep experiments have been carried out over hardened samples with the micro-indentation technique validated for long-term basic creep [27].

\section{Materials and methods}

$\mathrm{CaCO}_{3}$ cement samples with diverse mixture design (varied ACC:V wt.\% ratio) have been prepared and conditioned at different relative humidities (RH). After setting; a first set of samples have been used to evaluate their compressive strength using uniaxial compressive strength tests; while a second set have been used to assess their long-term creep deformation properties via micro-indentation ( $\mu$-indentation) tests.

\subsection{Preparation of $\mathrm{CaCO}_{3}$ reagent powders and cement samples}

The preparation of $\mathrm{CaCO}_{3}$ cements requires the synthesis of different calcium carbonate polymorphs in order to design the initial cement mixture [9]. Accordingly; both ACC and vaterite phases were prepared as described in [28]. Briefly; they were precipitated by double decomposition between calcium chloride $\left(\mathrm{CaCl}_{2} \cdot 6 \mathrm{H}_{2} \mathrm{O}\right.$; Sigma Aldrich) and sodium carbonate $\left(\mathrm{Na}_{2} \mathrm{CO}_{3}\right.$; Sigma Aldrich) equimolar $(0.5 \mathrm{M})$ solutions at room temperature using a magnetic stirrer set at $400 \mathrm{rpm}$. The reaction time was just $10 \mathrm{sec}$ for ACC and $30 \mathrm{~min}$ for vaterite taking as a reference Ogino et al. studies [29]. To wash off any dissolved sodium chloride $(\mathrm{NaCl})$; the $\mathrm{CaCO}_{3}$ precipitates were rinsed under vacuum with deionized water and ethanol; using a filtering kit and $0.5 \mu \mathrm{m}$ pore-size filter papers (Millipore; USA). Subsequently; the $\mathrm{CaCO}_{3}$ precipitates were flushed with liquid $\mathrm{N}_{2}$ to block any evolution of these metastable phases. The frozen precipitates were lyophilized (Alpha 1-4 LD plus; Martin Christ; Germany) for $48 \mathrm{~h}$ at $0.05 \mathrm{mbars}$ and $-50{ }^{\circ} \mathrm{C}$ and stored in a freezer $\left(-22^{\circ} \mathrm{C}\right)$ with additional silica powder bags prior to cement manufacturing.

The precipitates were scanned by X-ray diffraction (XRD) (Bruker D8 Discover X-ray diffractometer) to identify the crystalline phases present using $\mathrm{Cu} \mathrm{K \alpha}$ radiation $(30 \mathrm{~mA}$ and $40 \mathrm{kV})$ and recording $2 \theta$ angles from 20 to $50^{\circ}$ at a $0.04 \mathrm{~s}^{-1}$ sweep rate. Additionally; they were imaged with scanning electron microscopy (SEM) (Hitachi SU5000 Field-Emission; $1 \mathrm{kV}$ acceleration voltage and $3.0 \mathrm{~mm}$ working distance). 
$\mathrm{CaCO}_{3}$ cements with different microstructures were synthesized by mixing $\mathrm{ACC}$ and vaterite powders in different weight ratios (wt.\%): 1:1; 1:2 and 1:3; respectively; with distilled water keeping a water-to-powder ratio; $w / p$; of 0.5 . Just after mixing the powders with the liquid phase; the resulting pastes were viscous and easily mouldable for several minutes and they were placed in specially designed oedometric presses (Figure 1) in between two porous; plastic-made; auxiliary discs. The inner walls of the presses were coated with Teflon ${ }^{\circledR}$. A steel spring loaded the assembly uniaxially. Using the spring constant of the spring and the surface of the auxiliary discs it was estimated that the sample was under a stress value of approximately 0.15 $\mathrm{MPa}$. The specimens were unmolded after $24 \mathrm{~h}$ and left under atmospheric conditions for final drying (21 ${ }^{\circ} \mathrm{C}$; $\left.\sim 55 \% \mathrm{RH}\right)$. This process was followed by means of their weight evolution using digital scales (Sartorious Lab Instruments; Germany; accuracy $=0.1 \mathrm{mg}$ ). After 28 days of drying; a first set of samples were cut into smaller cylinders using a metallic saw and polishing paper (silicon carbide P80D) brought to $1.00 \pm 0.02 \mathrm{~cm}$ in height and $0.50 \pm 0.02 \mathrm{~cm}$ in diameter to perform compressive strength tests; while a second set were brought to $1.00 \pm 0.02 \mathrm{~cm}$ in height and $2.00 \pm 0.02 \mathrm{~cm}$ in diameter to carry out $\mu$-indentation tests. The final dimensions of the specimens were measured using a calliper and used to determine their apparent density; $\rho_{\mathrm{a}}$. To ensure reproducibility; sufficient cement quantities were made to perform all analyses on the same sample batch. 


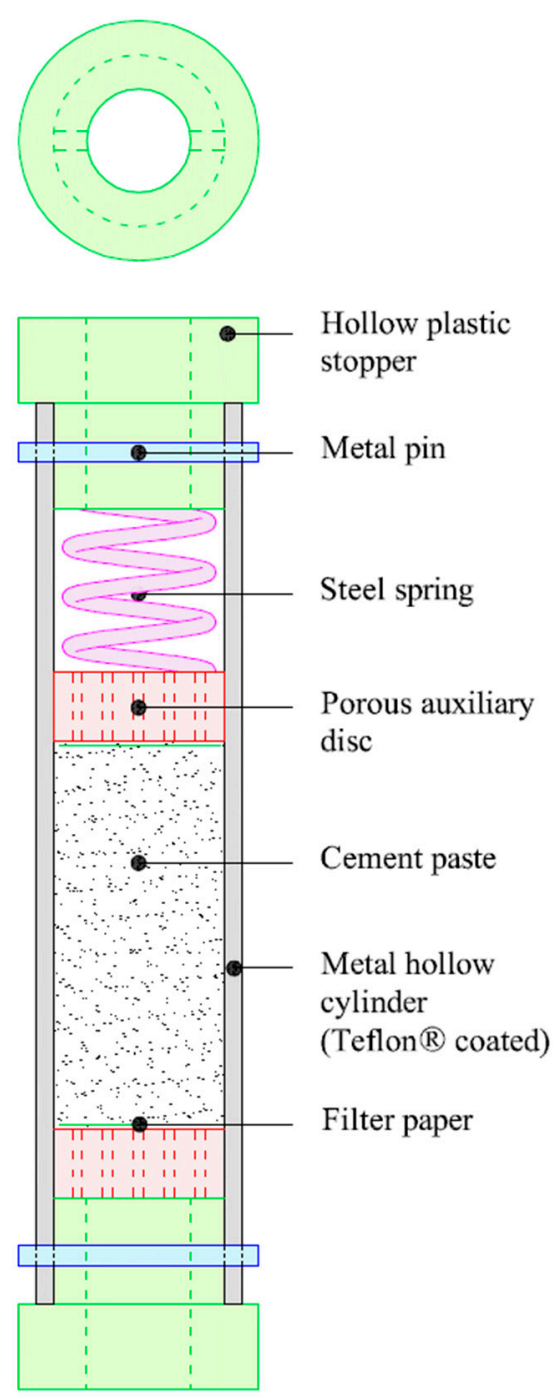

Figure 1. Schematic drawing of the oedometric press designed to cast $\mathrm{CaCO}_{3}$ cements. The main body is a metallic hollow cylinder $\left(12.0 \mathrm{~cm}\right.$ in height and $2.0 \mathrm{~cm}$ inner diameter) coated with Teflon ${ }^{\circledR}$ spray. The cement paste is compacted in between two porous plastic discs and the assembly is loaded by a steel spring with the aid of two plastic stoppers at the edges.

\subsection{Uniaxial compressive strength tests}

To evaluate the elastic modulus; $E$; and the uniaxial compressive strength; $Y$; of hardened $\mathrm{CaCO}_{3}$ cement compositions prepared as described on the previous section (cylinders with $1.00 \pm 0.02 \mathrm{~cm}$ in height and $0.50 \pm 0.02 \mathrm{~cm}$ in diameter); uniaxial compression tests were carried out using a DEBEN CT5000 (UK) tensile/compression stage $(5000 \mathrm{~N}$ load cell; $0.01 \mathrm{~N}$ resolution); at a crosshead speed of $0.2 \mathrm{~mm} / \mathrm{min}$; corresponding to strain rates of $10^{-3} \mathrm{~s}^{-1}$. Three samples of each composition were tested to ensure repeatability.

\subsubsection{Data analysis}

From the recorded data (applied force and elongation); a stress-strain curve was constructed for each test. Figure 2 shows an example stress-strain curve constructed for one of the indentations performed at $54 \% \mathrm{RH}$ to an specimen with an starting composition ACC:V 1:3 wt.\%. 


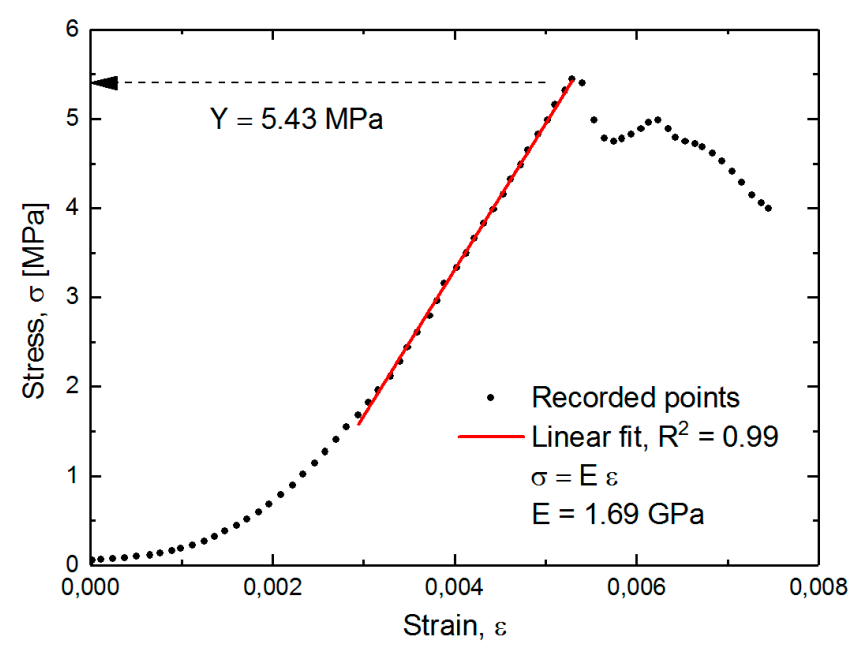

Figure 2. Stress-strain; $\sigma-\varepsilon$; curve constructed from the applied force and elongation recorded during uniaxial compressive test of a $\mathrm{CaCO}_{3}$ cement sample with a starting composition ACC:V 1:3; conditioned and tested at $54 \%$ RH. The red solid line represents the best fit performed to determine the elastic modulus; $E$; of the sample while the dashed arrow indicates its compressive strength; $Y$.

As shown; the initial relationship between the stress and the strain follows a curved trend which can be explained as a geometrical re-adjustment between the sample and the machine's jaws typically due to a lack of parallelism within the sample's top and bottom surfaces. Eventually; the relationship become linear being the elastic modulus; $E$; the proportional factor between the two parameters: $\sigma=E \cdot \varepsilon$. Consequently; the elastic modulus; $E$; can be calculated from the slope of this linear region. More specifically; it has been calculated using the "straight line fitting - least squares" method described in [30].

With increasing stress; the sample begins to deform plastically and the curve deviates from linearity. This point is known as the yield point and represents the compressive strength; $Y$; of the specimen. The dashed arrow on Figure 2 indicates the stress hold by the sample by the end of the elastic regime. Both the elastic modulus; $E$; and compressive strength; $Y$; were extracted from the curves using an in-house developed script in Matlab®.

\subsection{Micro-indentation creep experiments}

\subsubsection{Sample conditioning}

Prior to $\mu$-indentation tests; one specimen of each composition was moved into a desiccator with a controlled relative humidity $(\mathrm{RH})$ for conditioning. The $\mathrm{RH}$ conditions were created by filling the desiccators with saturated aqueous salt solutions sufficient time in advance to equilibrate the desiccator atmosphere before moving the samples in. More specifically; the chemicals $\mathrm{MgCl}_{2} ; \mathrm{Mg}\left(\mathrm{NO}_{3}\right)_{2}$ and $\mathrm{KNO}_{3}$ were used to create $\mathrm{RH}$ of $33 \% ; 54 \%$ and $93 \%$; respectively; at the temperature of $23{ }^{\circ} \mathrm{C}[31]$.

In order to determine the duration of conditioning necessary for the samples to achieve moisture equilibrium with conditioning environment; the mass evolution of the three different samples being conditioned at $33 \%$ RH were measured in parallel with sample conditioning. 
The measurements showed very similar drying kinetics for the three compositions; which required 3 days to achieve moisture equilibrium with conditioning environment. Consequently; all samples were let for 5 days inside the desiccators to ensure total moisture equilibrium at each RH prior to microindentation creep experiments. Under these conditions; autogenous shrinkage during creep tests is avoided and hence the contact creep compliance; $L(t)$; only characterizes basic creep; i.e.; the deformation of the samples is exclusively due to the application of an external mechanical load.

\subsubsection{Measurement protocol}

Microindentation creep experiments were carried out using the indentation apparatus in Lafarge Research Center (France) [32]. It is equipped with a motor controller; a monitoring system; an indentation platform and a removable chamber for relative humidity control during indentation. The indentation platform consists of a sample-mounting board; a force sensor and a displacement sensor. Prior to the experiments; the microindenter was calibrated according to the ASTM standard E 2546-07 [33] and its compliance was determined according to Kalidindi et al. [34].

After sample conditioning; microindentation creep experiments were carried out in relative-humiditycontrolled environment by circulating air with controlled RH inside the indentation chamber. The air was obtained by pumping dry $\mathrm{CO}_{2}$-free air into saturated salts solutions [32].

On each sample; 10 microindentation tests were performed on a different location with a Vickers indenter probe; applying a maximal force of $1 \mathrm{~N}$. Based on previous studies [35-37]; this value is low enough to ensure proportionality between creep strain and applied stress. For each indent; the load was increased linearly over time at a rate equal to $10 \mathrm{~N} / \mathrm{min}$; kept constant during the holding phase; and decreased linearly over time back to zero at the same rate as the loading one. Out of the 10 indents performed on each sample; 5 were with a relatively short 20 -sec-long holding phase; while 5 were performed with a relatively long 180 sec-long holding phase.

\subsubsection{Data analysis}

Figure 3 shows the evolution of the indentation depth; $h$; with the applied load; $P$; recorded from a microindentation test performed on a sample with an starting composition ACC:V 1:1 wt.\%; conditioned and tested at $54 \% \mathrm{RH}$. In this figure; $\mathrm{h}=0$ stands for the onset of contact between the indentation probe and the sample. Moreover; the three phases of the test - loading; holding and unloading - are represented with different colours to facilitate their identification. 


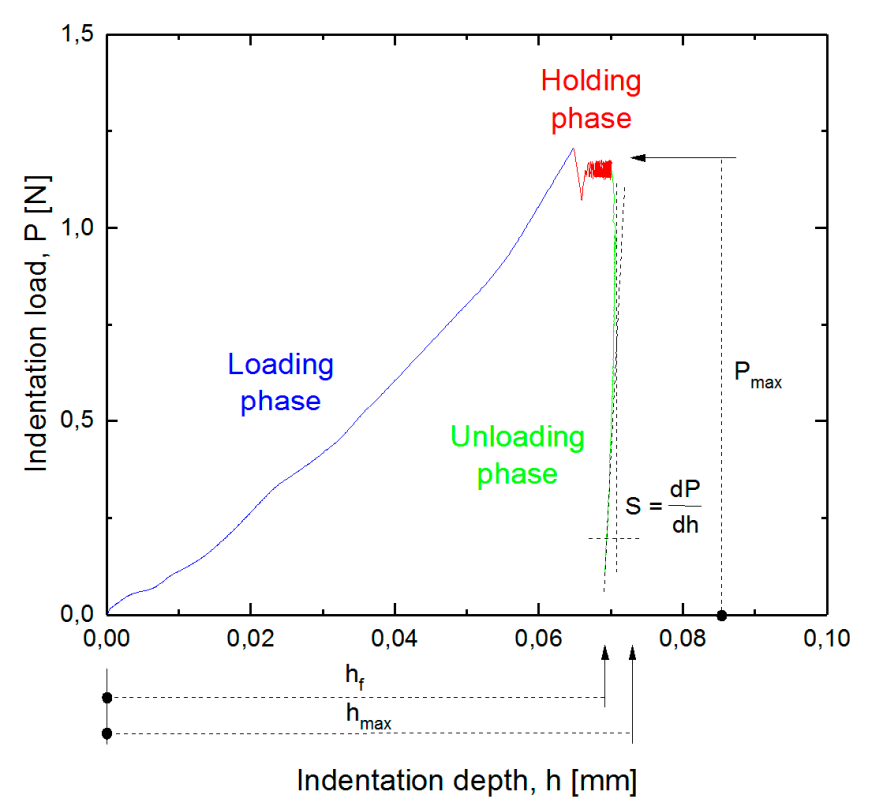

Figure 3. Indentation load; $P$; as function of indentation depth; $h$; recorded during a microindentation experiment over a $\mathrm{CaCO}_{3}$ sample with an starting composition ACC:V 1:1 wt.\% previously conditioned at $54 \%$ RH. The quantities shown are: the peak indentation load; $P_{\max }$; the indenter maximum displacement at peak load; $h_{\max }$; the final depth of the contact impression after unloading; $h_{f}$; and the unloading stiffness of the sample; $S$.

\subsubsection{Assessment of time-independent properties}

The mechanical problem involved in indentation testing is a typical problem of contact mechanics: the indentation probe penetrates into a flat surface of a material of interest and then is withdrawn from the surface. Galin et al. [38] presented; for the first time; a solution for the indentation of an elastic half-space by a rigid axisymmetric indentation probe. If the latter is characterized by $\mathrm{z}=\mathrm{g}_{0} \cdot \mathrm{r}^{\mathrm{g}}$ with $\mathrm{r}$ being the radius; $\mathrm{g}_{0}$ and $\mathrm{g}$ being geometry coefficients; the following equation links the indentation load; $P$; to indentation depth; $h$; via the effective modulus; $E_{\text {eff }}$, and parameters depending on the geometry of the indenter:

$$
P=\varphi \cdot E_{\text {eff }} \cdot h^{1+1 / g}
$$

where $\varphi$ represents a constant parameter which includes the Euler Gamma function. A differentiation of the equation above with respect to the indentation depth; $h$; gives [39]:

$$
S=\frac{d P}{d h}=\frac{2}{\sqrt{\pi}} \cdot E_{e f f} \cdot \sqrt{A_{c}}
$$

where $S$ is the contact stiffness defined by $S=d P / d h$; and $A_{c}$ is the projected contact area (or briefly; contact area) between the indentation probe and the indented surface. Moreover; the effective modulus; $E_{\text {eff; }}$ can be linked to the Elastic modulus; E; by the following equation:

$$
\frac{1}{E_{e f f}}=\frac{1-v_{i n}^{2}}{E_{\text {in }}}+\frac{1-v^{2}}{E}
$$

where $v_{\text {in }}$ and $v$ are the Poisson's ratio of the indentation probe and that of the tested material; respectively; $E_{i n}$ and $E$ are the Elastic modulus of the indentation probe and that of the tested material; respectively. For a 
rigid indentation probe; Eq. 3 can be simplified as the following; in which $M$ is termed as the indentation modulus:

$$
E_{\text {eff }} \cong \frac{E}{1-v^{2}}=M
$$

Another time-independent property which can be assessed is the indentation hardness; $H$. It is defined as the average pressure below the indenter and can be calculated with the following equation:

$$
H=\frac{P_{\max }}{A_{c}}
$$

Consequently; the short (20-sec-long) holding phase tests enabled us to determine the Elastic modulus; $E$; with Eq. 2 and Eq. 4 and the hardness; $H$; with Eq. 5; of the different cement compositions assuming a Poisson's ratio $v=0.20$ for all of them.

\subsection{Determination of the projected contact area; $A_{c}$ : the Oliver and Phaar method}

To determine the Elastic modulus; $E$; and the hardness; $H$; we need to find out the projected contact area; $A_{c}$. In the present study the method introduced by Oliver and Pharr [40] has been used. As presented on Figure 4; in this method the indentation depth; $h$; can be decomposed into two parts: a depth $h_{\mathrm{C}}$ over which the indentation probe is in contact with the indented surface and a depth $\mathrm{h}_{\mathrm{S}}$ over which the probe is not in contact with the indented surface:

$$
h=h_{C}+h_{S}
$$

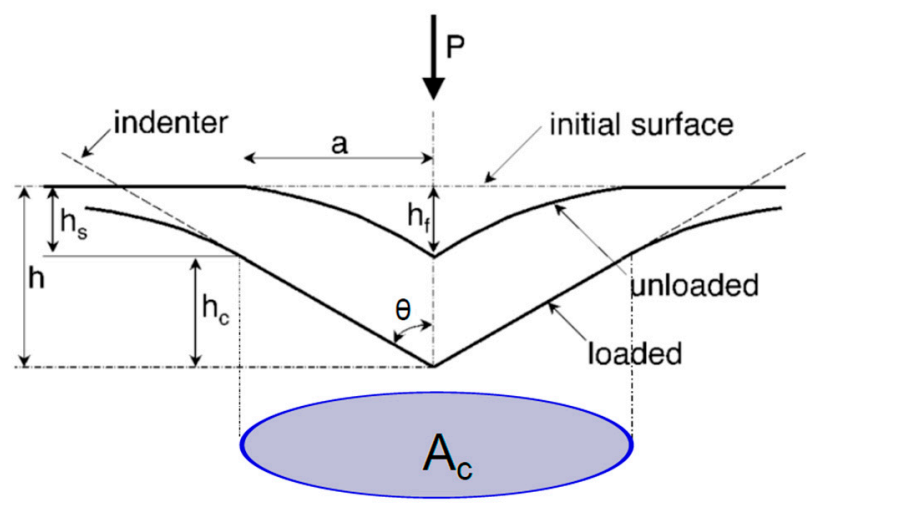

Figure 4. Schematic representation of a section through an indentation showing various parameters used in Oliver and Pharr method; schematic adapted from [40].

Applying the solution of Sneddon [41] for a conical indentation probe; the depth $\mathrm{h}_{\mathrm{S}}$ over which the probe is not in contact with the indented surface can be linked to the residual depth $h_{f}$ of the indent after withdrawing the indentation probe (See Figure 3):

$$
h_{s}=\frac{\pi-2}{\pi} \cdot\left(h-h_{f}\right)=\frac{\pi-2}{2 \pi} \cdot \frac{P}{S}
$$

Deriving from Sneddon's load-displacement relation expressed in Eq. 1 and applying it for a conical indentation probe yields: 


$$
h_{c}=h_{\max }-\varepsilon \cdot \frac{P_{\max }}{S_{\max }}
$$

where $S_{\text {max }}=\left.\frac{d P}{d h}\right|_{P=P_{\max }}$ is the maximum contact stiffness at the maximum load and the parameter $\varepsilon$ depends on the geometry of the indentation probe; being equal to 0.72 for a conical indentation probe. Thus; Eq. 8 offers a method to estimate the contact depth between indenter and indented surface and it can be used to determine the projected contact area; $A_{c}$. The relationship between $h_{C}$ and $A_{c}$ is known as the shape area function; $A_{c}\left(h_{C}\right)$; and it has different values depending on the geometry of the indenter. For the Vickers indentation probe used here; its value is the following:

$$
A_{C}\left(h_{c}\right)=24.5 h_{c}^{2}
$$

\subsubsection{Assessment of time-dependent properties}

Indentation tests can also be used to measure the creep properties of materials. By introducing a fictitious indentation test with an instantaneous loading phase; an instantaneous unloading phase and an instantaneousreloading-and holding phase; Vandamme et al. [42] derived a method to back-calculate creep properties from an indentation in which time-independent plasticity occurs.

The main assumption in their derivation is that time independent plasticity occurs only during the loading phase but not during the holding nor unloading phases. Their demonstration starts by writing; in the case of elastic indentation; the contact radius; $\mathrm{a}_{\mathrm{c}}$; as a function of indentation depth: $a_{c}=f(h)$.

The analytical expression of the function $f$ is generally unknown; but it is not necessary in the derivation. Integrating Eq. 2 with respect to indentation depth; $h$; yields: $P=2 M F(h)$; where $F(h)$ is the primitive function of $f(h)$ for which $F(0)=0$. Rewriting the yield expression in the time domain for a linear viscoelastic material by applying the correspondence principle; one obtains:

$$
P(t)=2 \int_{0}^{t} M(t-\tau) \frac{d}{d \tau} F(h(\tau)) d \tau
$$

Performing Laplace transform to Eq. 10; one obtains:

$$
\mathcal{L}(P(t))=2 s \cdot \mathcal{L}(M(t)) \mathcal{L}(F(h(t)))
$$

In the case of a step load; one can link the contact creep compliance; $L(t)$; to indentation data in Laplace domain. By performing inverse Laplace transform; one obtains the time-dependent contact creep compliance in the time domain as a function of indentation depth during the holding phase:

$$
L(t)=\frac{2 F(h(t))}{P_{\max }}
$$

After differentiating the previous equation with respect to time; one obtains the relation of interest which links the derivative of the contact creep compliance to the rate of penetration of the indentation probe during the holding phase [42]: 


$$
\hat{\mathrm{L}}(t)=\frac{d}{d t} \frac{2 F(h(t))}{P_{\max }}=\frac{2 f(h(t) \cdot \mathrm{h}(t)}{P_{\max }}=\frac{2 a_{c}(t) \cdot \mathrm{h}(t)}{P_{\max }}
$$

where $\mathrm{a}_{\mathrm{c}}$ is the radius the projected contact area; $\mathrm{A}_{\mathrm{c}}$. Excluding a flat punch; $a_{c}(t)$ evolves with $h_{c}$; but assuming that it does not change too much during the holding phase is realistic. Then; the contact radius during holding can therefore be estimated by the contact radius at the start of unloading and can be estimated by the Oliver and Pharr's method [40]. Integrating Eq. 13 with respect to time from the beginning of holding phase yields:

$$
L(t)-L(0)=L(t)-\frac{1}{M_{0}}=\frac{2 a_{c} \Delta h(t)}{P_{\max }}
$$

where $\Delta h(t)$ is the change of indentation depth during the holding phase. The difference $L(t)$ - $L(0)$ between the contact creep compliance $L(t)$ and the reciprocal of indentation modulus $L(0)=1 / M_{0}$ at the moment of loading is termed the contact creep function. The use of Eq. 14 to back-calculate creep properties enables to obtain a contact compliance which is a material property.

Thus; 180-sec-long holding phase indents were used in the present study to measure the change of indentation depth; $\Delta h(t)$; during the holding phase and to subsequently calculate the contact creep function; $L(t)-L(0)$. Moreover; since this function is logarithmic with respect to time; it could be fitted to the following equation; which allowed a quantitative comparison of the characteristic parameters of each sample:

$$
L(t)-\frac{1}{M_{0}}=\frac{\ln \left(t / \tau_{i}+1\right)}{C_{i}}
$$

where $C_{i}$ represents the contact creep modulus and $\tau_{i}$ is the characteristic creep time. The former provides an idea about the amplitude of the creep function; so that low creep rates are represented by large creep modulus values; while the latter represent the length of the transient period required to reach the logarithmic kinetics of creep. It is worth mentioning that the characteristic creep time; $\tau$; is not a universal parameter but depends on the applied stress. Since we have applied the same stress to all compositions; their characteristic creep time; $\tau$; values are still comparable.

\section{Results}

The synthesized amorphous calcium carbonate; ACC; and vaterite; V; polymorphs; necessary to manufacture $\mathrm{CaCO}_{3}$ cements are introduced. Afterwards; the compressive strength and the elasticity of the set cement samples are presented. Finally; the elastic and creep strain results obtained from microindentation tests are shown as function of the sample microstructure and moisture equilibrium with relative humidity.

\subsection{Characterization of $\mathrm{CaCO}_{3}$ precipitates}

As shown in [28]; ACC precipitates (Figure 5A) consist of equidimensional spherical nanoparticles $(<50 \mathrm{~nm}$ in diameter) accompanied by rhombohedral crystals of about 50-100 $\mathrm{nm}$. These are interpreted to be calcite and confirmed by XRD analysis (Figure 5C). Vaterite precipitates (Figure 5B) consist of spherical grains of 
4-5 $\mu \mathrm{m}$ in diameter also accompanied by rhombohedral grains $(4-5 \mu \mathrm{m})$; which are calcite according to the XRD scans (Figure 5C). Therefore; both ACC and vaterite precipitates are about $90 \%$ pure (from XRD analysis) with only minor amounts of calcite.
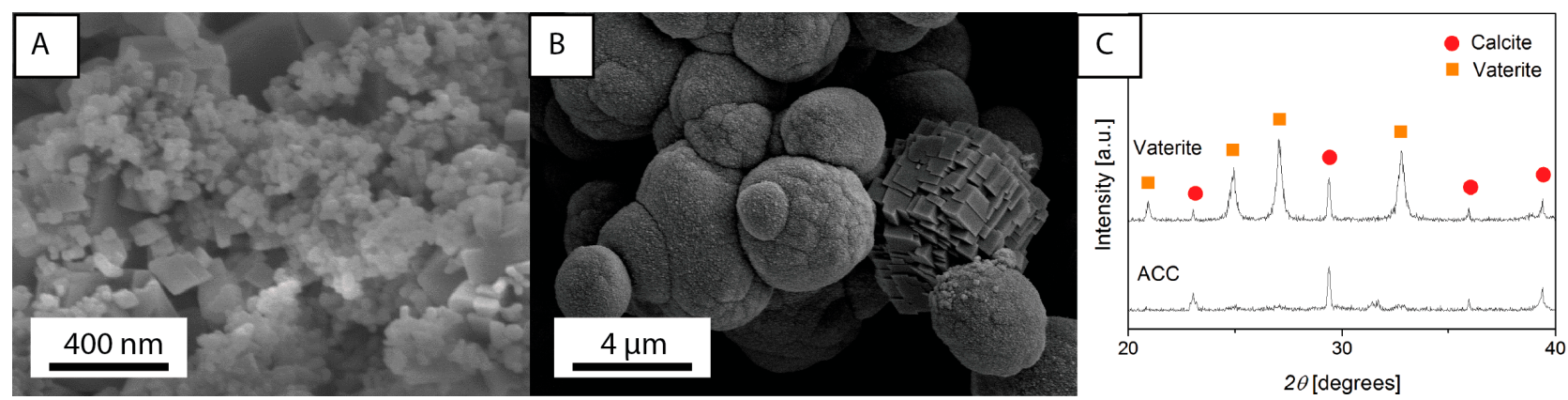

Figure 5. SEM micrographs of synthesized calcium carbonate powders in the form of (a) ACC phase and (b) Vaterite phase. (c) XRD patterns of (a) and (b) powders.

\subsection{Uniaxial compressive strength tests on $\mathrm{CaCO}_{3}$ cement}

The compressive strength; $Y$; and the elastic modulus; $E$; of three $\mathrm{CaCO}_{3}$ cement compositions have been calculated from uniaxial compressive tests. Figure 6 shows the elastic modulus; $E$; and compressive strength; $Y$; values obtained following the previous methodology for the different cement compositions tested in the present study as function of their initial vaterite weight fraction; $X_{V}$. Moreover; Table 1 includes a summary of the results to facilitate their comparison with the elastic parameters obtained from microindentation experiments.

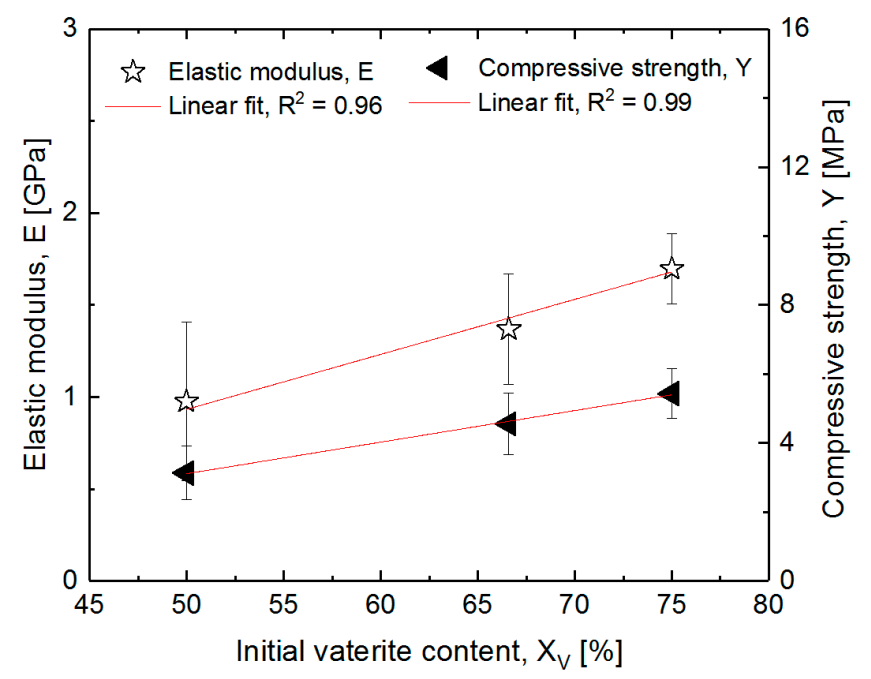

Figure 6. Elastic modulus; $E$; and compressive strength; $Y$; extracted from uniaxial compression tests for three $\mathrm{CaCO}_{3}$ cements conditioned at $54 \% \mathrm{RH}$; as function of their initial vaterite content; $X_{V}$.

The results show a clear trend: a larger starting amount of vaterite; $X_{V}$; causes more elastic and resistant specimens. Indeed; the results show that the elastic modulus; $E$; and the compressive strength; $Y$; follow a linear relationship with this variable. The elastic modulus yields the relation $E_{i}=0.029 \cdot \mathrm{X}_{\mathrm{V}}-0.560 \mathrm{GPa}\left(\mathrm{R}^{2}\right.$ $=0.96)$; while the compressive strength $\mathrm{Y}_{\mathrm{i}}=0.091 \cdot \mathrm{X}_{\mathrm{V}}-1.462 \mathrm{MPa}\left(\mathrm{R}^{2}=0.99\right)$. 


\subsection{Microindentation experiments on $\mathrm{CaCO}_{3}$ cement.}

Figure 7 shows the evolution of the indentation depth; $\Delta h$; with time; $t$; during the holding phase of indentation experiments performed on $\mathrm{CaCO}_{3}$ cement samples with dissimilar starting compositions but all conditioned and tested at $54 \% \mathrm{RH}$. In this figure; $\mathrm{t}=0 \mathrm{~s}$ stands for the onset of the holding phase and the corresponding indentation depth; $h$; is normalized to $0 \mathrm{~mm}$.

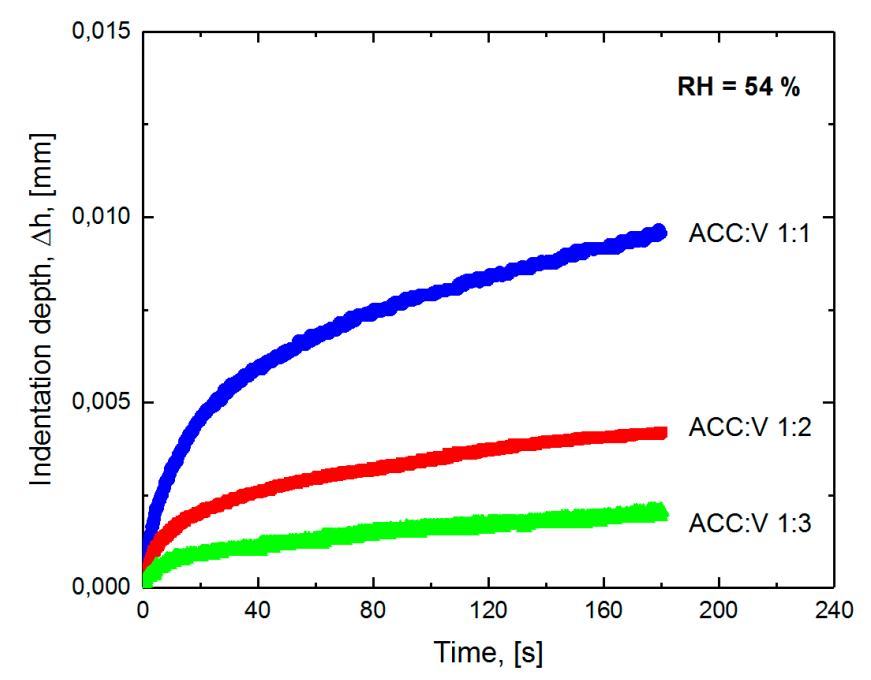

Figure 7. Indentation depth; $\Delta$; as function of time during the holding phase of microindentation tests performed on $\mathrm{CaCO}_{3}$ cement samples with diverse starting composition $(1: 1 ; 1: 2$ and $1: 3 \mathrm{wt} \%$ ACC:V) all conditioned at $54 \%$ RH.

As observed; the indentation depth reached during the holding phase decreases for samples with a larger staring amount of vaterite; $X_{V}$; within the cement mixture design. These results; indeed; follow the same trend reported for the elastic modulus; $E$; and compressive strength; $Y$. From these data; the contact creep functions; $L(t)-1 / M_{0}$; yielded by the three different $\mathrm{CaCO}_{3}$ cement samples were determined using Eq. 14 and plotted in Figure 8. The results show that for a given relative humidity; the amplitude of creep decreases with the initial amount of vaterite within the cement mixture design. Moreover; the contact creep functions; $L(t)-1 / M_{0}$; determined for every composition and environmental condition tested were fitted into equation 15 (yellow dashed lines) to get the correspondent contact creep modulus; $C_{i}$; and the characteristic creep time; $\tau_{i}$. 


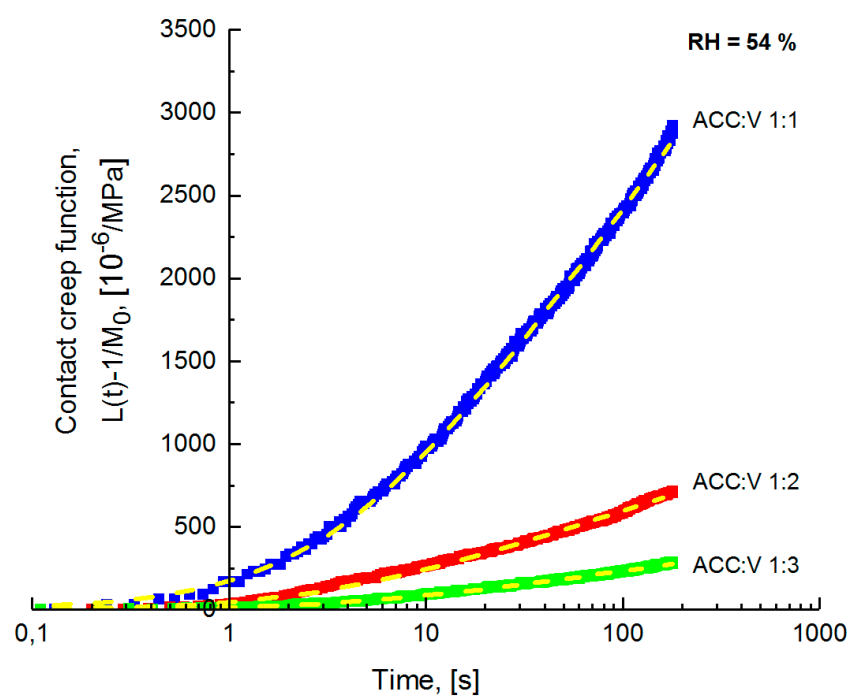

Figure 8. Contact creep functions $L(t)-1 / M_{0}$ of $\mathrm{CaCO}_{3}$ cement samples with diverse starting composition $(1: 1 ; 1: 2$ and $1: 3$ wt\% ACC:V) conditioned and tested at 54\% RH; obtained by microindentation tests. For each sample; out of the 5 experiments performed; only the median curve is displayed. The dashed lines represent the best fits to Eq. 15.

Table 1 includes a summary of all results obtained from both uniaxial compression tests (elastic modulus; $E$; and uniaxial compressive strength; $Y$ ) and microindentation tests (contact creep modulus; $C_{i}$; characteristic creep time; $\tau_{i}$; elastic modulus; $E$; and hardness; $H$ ) as function of the relative humidity and $\mathrm{CaCO}_{3}$ initial mixture design (ACC:V wt.\%).

Table 1. Elastic modulus; E; and compressive strength; $Y$; of $\mathrm{CaCO}_{3}$ cement samples obtained from uniaxial compressive strength tests at $54 \%$ RH. Contact creep modulus; $C_{i}$; characteristic creep time; $\tau$; elastic modulus; E; and hardness; $\mathrm{H}$; of $\mathrm{CaCO}_{3}$ cement samples conditioned and tested at 33\%; 54\% and 93\% RH; obtained from microindentation tests. *Reference microindentation results from a Portland cement sample with the same water to powder ratio as $\mathrm{CaCO}_{3}$ cements are also included [27].

\begin{tabular}{|c|c|c|c|c|c|c|c|c|}
\hline $\begin{array}{l}\text { Relative } \\
\text { Humidity }\end{array}$ & \multicolumn{2}{|c|}{ Sample } & \multicolumn{2}{|c|}{ Uniaxial compression tests } & \multicolumn{4}{|c|}{ Microindentation tests } \\
\hline RH (\%) & $\begin{array}{l}\text { Initial } \\
\text { ACC:V } \\
\text { (wt.\%) }\end{array}$ & $\begin{array}{l}\text { water/ } \\
\text { powder } \\
\text { ratio }\end{array}$ & $\mathrm{E}$ [GPa] & $\mathrm{Y}[\mathrm{MPa}]$ & $\mathrm{Ci}[\mathrm{GPa}]$ & $\tau[\mathrm{s}]$ & $\mathrm{E}[\mathrm{GPa}]$ & $\mathrm{H}[\mathrm{MPa}]$ \\
\hline \multirow{3}{*}{33} & $1: 1$ & 0.5 & - & - & $8.15 \pm 1.33$ & $2.46 \pm 0.04$ & $1.48 \pm 0.44$ & $16.73 \pm 1.54$ \\
\hline & $1: 2$ & 0.5 & - & - & $45.10 \pm 7.30$ & $1.59 \pm 0.89$ & $1.77 \pm 0.40$ & $18.46 \pm 1.12$ \\
\hline & $1: 3$ & 0.5 & - & - & $82.71 \pm 16.40$ & $0.57 \pm 0.03$ & $1.79 \pm 0.58$ & $20.73 \pm 0.88$ \\
\hline \multirow{4}{*}{54} & $1: 1$ & 0.5 & $0.97 \pm 0.43$ & $3.13 \pm 0.78$ & $1.17 \pm 0.32$ & $7.39 \pm 0.89$ & $0.84 \pm 0.15$ & $5.89 \pm 1.01$ \\
\hline & $1: 2$ & 0.5 & $1.36 \pm 0.30$ & $4.55 \pm 0.90$ & $5.51 \pm 0.44$ & $2.05 \pm 0.84$ & $1.66 \pm 0.49$ & $13.30 \pm 1.85$ \\
\hline & $1: 3$ & 0.5 & $1.69 \pm 0.19$ & $5.43 \pm 0.72$ & $9.97 \pm 1.31$ & $1.55 \pm 0.32$ & $2.51 \pm 0.58$ & $18.05 \pm 2.15$ \\
\hline & P50-0SV* & 0.5 & - & - & $20.89 \pm 3.19$ & $2.40 \pm 0.80$ & $10.55 \pm 0.74$ & $134.3 \pm 7.16$ \\
\hline \multirow{3}{*}{93} & $1: 1$ & 0.5 & - & - & $0.053 \pm 0.008$ & $18.06 \pm 1.06$ & $0.078 \pm 0.024$ & $3.17 \pm 0.59$ \\
\hline & $1: 2$ & 0.5 & - & - & $0.075 \pm 0.012$ & $12.07 \pm 1.32$ & $0.882 \pm 0.052$ & $3.66 \pm 1.19$ \\
\hline & $1: 3$ & 0.5 & - & - & $0.135 \pm 0.017$ & $7.06 \pm 2.63$ & $1.030 \pm 0.179$ & $3.78 \pm 0.31$ \\
\hline
\end{tabular}




\section{Discussion}

\subsection{Compressive strength and elasticity of $\mathrm{CaCO}_{3}$ cement}

As stated previously; the results included on Figure 6 show a clear trend: a larger starting amount of vaterite; $X_{V}$; causes more elastic and resistant specimens. The origin of such behaviour seems to be related with some findings we introduced on a previous publication [28].

In this study; we characterized the (re)crystallization kinetics of ACC and vaterite phases into calcite and the rigidity development during setting of $\mathrm{CaCO}_{3}$ pastes with the same mixture design as the ones tested here (ACC:V 1:1; 1:2 and 1:3 wt.\%). We suggested "crystal bridging" [43] as the mechanism ruling the structural development of the pastes during the setting reaction and it could be deduced that a faster (re)crystallization process; induced by a larger initial amount of vaterite; enhanced the bridging mechanism during setting. We hypothesized that a larger initial amount of vaterite induced calcite crystals to get in contact since earlier stages and subsequent crystal growth resulted on joints with a larger contact area.

Indeed; this hypothesis agrees well with the results here presented. Samples with increasing initial vaterite content can withstand greater mechanical loads than those with lower amounts. Despite the fact that all tested samples were entirely composed of calcite by the end of the setting reaction; the results here included suggest that the history of the (re)crystallization determines the mechanical properties of $\mathrm{CaCO}_{3}$ cements.

The apparent density; $\rho_{\mathrm{a}}$; of all compositions is within $1.66 \pm 0.06 \mathrm{~g} / \mathrm{cm}^{3}$ regardless of their initial design. Comparing this value with the density of pure calcite $\left(2.71 \mathrm{~g} / \mathrm{cm}^{3}\right)$ [44]; a porosity; $\phi$; of about $39 \%$ can be deduced for all of them. The elasticity of the three $\mathrm{CaCO}_{3}$ cements evaluated ranged from 1000 to 1700 $\mathrm{MPa}$; whereas Baud et al. [45] reported a range within $\sim 80-200 \mathrm{MPa}$ for Leitha limestone measured from UCS tests. On the other hand; the compressive strength values measured by Baud et al. for limestone varied from $50 \mathrm{MPa}$ to $16 \mathrm{MPa}$ for samples with porosity; $\phi$; ranging from 18 to $31 \%$; whereas the values we obtained for $\mathrm{CaCO}_{3}$ cements are just within 3-6 MPa. Thus; these results suggest that the mechanical differences within the $\mathrm{CaCO}_{3}$ cements must be due to their diverse crystal joint strength given that they all yielded similar porosity.

Even though the mechanical properties of $\mathrm{CaCO}_{3}$ cement still reminds weak in comparison with other alternatives; from the previous interpretation it seems feasible to enhance them by bringing the pastes under pressure during the setting reaction. For example; Ishikawa et al. [46] interconnected calcite granules by exposing them to acidic calcium phosphate solutions under different pressures. The compressive strength of the set aggregates increases with the loading stress during setting until a critical value; above which the intermediate phase cannot be formed in between the granules resulting in weaker bonds. However; within $\mathrm{CaCO}_{3}$ cements; the calcite phase acts both as the granules and the binder simultaneously; so no critical loading should be expected. In any case; further studies are still necessary to check this approach. 


\subsection{Long-term creep properties of $\mathrm{CaCO}_{3}$ cement.}

The results included on Figure 8 show that creep is logarithmic with respect to time; which is a reminiscent of the long-term basic creep behaviour of cementitious materials [22;26]. Moreover; the results confirm that minutes-long microindentation creep experiments are long enough to reach the long-term creep behaviour of cement pastes; as it was demonstrated before [27]. Although one might think that this feature is due to the fact the microindentation just probes small volumes; Vandamme and Ulm [47] claimed that the origin is due to the large stresses that microindentation probes can apply to those volumes; allowing a faster redistribution of internal stresses within the solid.

\subsubsection{Effect of microstructure}

In this section; the results are discussed in terms of creep and elastic properties obtained by microindentation for three different cement microstructures conditioned and tested both under $54 \% \mathrm{RH}$.

For what concerns the creep properties; the best-fit parameters obtained for Eq. 15 are represented on Figure 9 as a function of the initial vaterite fraction; $X_{V}$; of the samples. At a glance; Figure 9 shows that the characteristic time needed to reach logarithmic kinetics varied greatly with the initial vaterite content. From about 7.5 seconds for the sample initially containing $50 \%$ of vaterite; it drops down to 2 seconds for the samples containing $\sim 67$ and $75 \%$ of vaterite. That means a breakdown by more than a factor 3.5 with the vaterite mole fraction; $X_{V}$. On the other hand; the contact creep modulus; $C$; raises from about $1 \mathrm{GPa}$ for the sample initially containing $\sim 50 \%$ of vaterite up to $10 \mathrm{GPa}$ for the cement which is mainly composed of vaterite; i.e.; an increase by factor 10. Thus; the amplitude of the creep rate of $\mathrm{CaCO}_{3}$ cements decreases with the increase of initial content of vaterite.

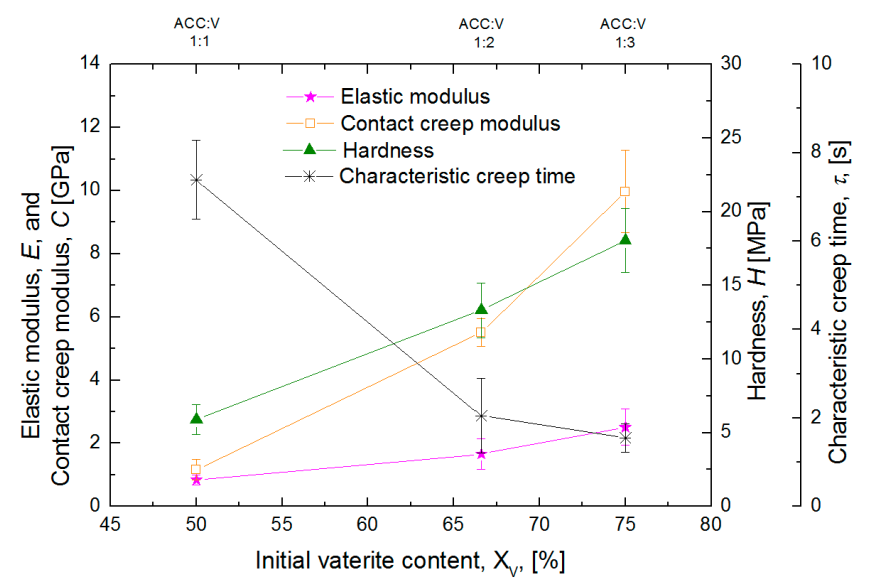

Figure 9 Young's modulus; E; Contact creep modulus; C; Indentation hardness; H; and Characteristic creep time; $\tau$; calculated from microindentation tests performed on three 28-day-old $\mathrm{CaCO}_{3}$ cements specimens $(1: 1 ; 1: 2$ and $1: 3 \mathrm{wt} \% A C C: V)$ as function of their final calcite mole fraction; $X_{i}$.

In Section 2.3.3. it was detailed how the elastic modulus; $E$; of the indented cement samples can be determined. The elastic modulus; $E$; and hardness; $H$; calculated from the short-holding-phase $\mu$-indentation tests; with assumption of Poisson's ratio $v=0.20$; are also included on Figure 9 and follow a similar drift as 
for the contact creep modulus; $C$. It is worth mentioning that the elastic modulus values; $E$; are in good agreement with those calculated from uniaxial compression tests; being the two-tailed P value between them of 0.6469 ; which by conventional criteria is considered to be not statistically significant (See Table 1). Regarding microindentation results; both the elastic modulus; $E$; and hardness; $H$; raise with the initial vaterite weight ratio. Nonetheless; the rise of the elastic modulus; $E$; is not as remarkable as that for the contact creep modulus; $\mathrm{C}$. A comparative study of those two moduli yields a linear relationship; as shown on Figure 10. All data points nicely align around the following equation: $E i=0.618 \cdot C i+0.180 \mathrm{GPa}$ with $\mathrm{R}^{2}=0.999$. Moreover; the evolution of the hardness; $H$; in comparison with the contact creep modulus; $C i$; seems also to follow a linear relationship; $\mathrm{Hi}=0.0046 \cdot \mathrm{Ci}+0.0012 \mathrm{GPa}$; although the coefficient of determination is slightly lower $\left(\mathrm{R}^{2}=0.90\right)$. Thus; both the elastic modulus; $E$; and the hardness; $H$; follow a linear relationship with the contact creep modulus; $\mathrm{C} i$. These relationships differ from the ones observed for C-S-H phases obtained by nanoindentation tests in Portland cements. Vandamme and Ulm [48] also found a linear relationship between the contact creep modulus; $\mathrm{Ci}$; and indentation hardness; $\mathrm{H}$; but a power law relation between the contact creep modulus; $\mathrm{C} i$; and elastic modulus; $E$. This fact highlights the diverse behaviour of the amorphous Portland phase and the crystalline $\mathrm{CaCO}_{3}$ cements against creep deformation.

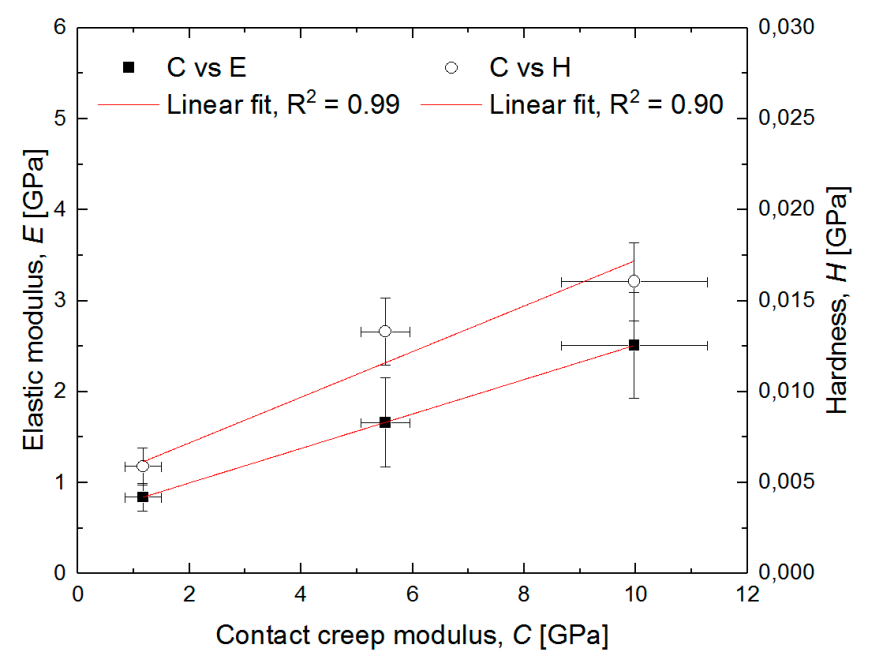

Figure 10. Contact creep modulus; $\mathrm{C}$; versus elastic modulus; $\mathrm{E}$; and hardness; $\mathrm{H}$; for $\mathrm{CaCO}_{3}$ cements with diverse ACC:V initial mixtures and in moisture equilibrium with $54 \%$ RH.

Since all tested samples were prepared with the same water-to-powder ratio $(w / p=0.5)$ and were conditioned for the same duration prior to the experiments; a similar moisture equilibrium; and therefore influence on creep strain; can be assumed for all of them. Moreover; cementitious materials are porous materials and their mechanical properties depend on this parameter. As recalled on the previous section; all $\mathrm{CaCO}_{3}$ cements develop a similar porosity under the maturation conditions here used so an analogous influence of this variable on creep deformation can also be assumed for all of them. Therefore; the differences among their creep functions must be due to their particular microstructure (composition and volume fraction of each phase) and the joint's strength among the $\mathrm{CaCO}_{3}$ grains after the setting reaction. An analogous dependence was found by Zhang [32]: diverse elastic modulus; $E$; hardness; $H$; and contact 
creep modulus; $C i$; values were reported for tricalcium silicate $\left(\mathrm{C}_{3} \mathrm{~S}\right)$ and dicalcium silicate $\left(\mathrm{C}_{2} \mathrm{~S}\right)$ pastes with the same porosity; remarking the importance of the solid phases; their volumetric distribution and the joints strength in controlling the final mechanical properties.

A multitude of creep theories have been proposed in the last century including; for example; the mechanical deformation theory; plastic theory; viscous and visco-elastic theory; solid solution theory; seepage theory; micro-cracking theory and long-term aging theory among many others [21-24]. However; none of them can explain all experimental observations and possible creep mechanisms. Since $\mathrm{CaCO}_{3}$ cements lack the amorphous C-S-H phase; the most probable creep mechanisms; according to the American Concrete Institute Committee [49]; can be a combination of microcraking in the early stages and dissolution and precipitation of calcite when is it under pressure in the long-term.

Under microindentation tests; a small region of the sample is subjected to large compressive stresses. The origin of the non-logarithmic part of the creep functions might be ascribed to cracking or microcracking of $\mathrm{CaCO}_{3}$ grain joints since many cementitious materials and rocks are known to be quasi brittle [37;50;51]. Thus; this mechanism is naturally affected by the amount and strength of grain joints. Similar time dependence for the growth of microcraks was reported by Bazant and co-workers for concrete samples [52]. Moreover; frictional grain boundary sliding may also occur if the frictional force between calcite grains is overcome; causing them to slide past each other [53]. However; this mechanism is more likely to occur at low effective stresses.

In the long-term; probably the best candidate to explain the creep of $\mathrm{CaCO}_{3}$ cements is the so-called theory of dissolution; transport and precipitation under pressure (or pressure solution theory); which is considered to be the most important one to explain the time dependent deformation of rocks [54-56]. The theory stands that the macroscopic creep is a result of the geometry change of the solid matrix (e.g. crystals) at microscopic scale. This change is driven at the microscale by chemical potential differences between the stressed and unstressed part of the solid and is governed by a mass transfer that occurs in three steps: i) dissolution of solid under pressure; ii) diffusion of dissolved mass through the interface of crystals or their aggregates [57] in a very thin liquid film [58]; and finally iii) precipitation at less stressed sites.

In this line; creep of $\mathrm{CaCO}_{3}$ cements can be due to the local dissolution of calcite crystals when they are stressed. Croize et al. [59] claimed that the deformation of calcite monocrystals occurs either by dissolution and diffusion along the contact calcite/indenter interface; i.e.; pressure solution; or by a combination of pressure solution and subcritical crack growth from the contact area toward less stressed parts of the crystal. It should be noted that calcite is a brittle mineral and the formation of microcracks on its surface under the indenter seems plausible. The authors also claimed that the occurrence of one or the other mechanism is not ruled by the applied stress but most likely by the presence or not of a flaw within the crystal. Thus; how the overall bridging area within a calcite crystal network regulate or influence the creep rate of $\mathrm{CaCO}_{3}$ cements might be rationalized in the following way: a lower bridging area favours local stress concentration and thus the sample can exhibit more creep. Dissolved $\mathrm{CaCO}_{3}$ grains can be transported and precipitated elsewhere. 
However; this process is much less likely to happen for larger overall contact areas since they will require higher loads to reach the same levels of stress concentration. For calcite monocrystals; the creep rate deformation has been reported to be diffusion-controlled [60] rather than dissolution-limited; despite of the low solubility of calcite. Therefore; a similar ruling step may be considered for calcite aggregates but further studies will be necessary to confirm this approach. In a similar way as for $\mathrm{CaCO}_{3}$ cements; PachonRodriguez et al. [61] showed that dissolution and precipitation under pressure is the main mechanism of creep of crystalline gypsum plaster.

In order to evaluate a possible upgrade of $\mathrm{CaCO}_{3}$ cements to commercial production; a comparison of the creep and elastic parameters must be done with OPC. Microindentation tests were carried out by Zhang et al. [27] for OPC samples. A contact creep modulus; $\mathrm{C} i$; of $\sim 20 \mathrm{GPa}$ was reported for a cement sample (P500SV) with the same water to cement ratio as the $\mathrm{CaCO}_{3}$ samples here tested $(\mathrm{w} / \mathrm{p}=0.5)$. That value is $\sim 20$ times larger than that obtained for the ACC:V 1:1 composition; but only double than the measured for the ACC:V 1:3 sample. Regarding the elastic modulus; E; the P50-0SV exhibited a value of about $11 \mathrm{GPa}$; whereas $\mathrm{CaCO}_{3}$ values are 12 to 4 times lower with increasing initial vaterite weight fraction. Thus; even though the ACC:V 1:3 composition shows the most similar properties; further strategies are still necessary to improve its performance before considering $\mathrm{CaCO}_{3}$ cements for industrial applications. A summary of all these values is listed on Table 1 .

\subsubsection{Effect of relative humidity}

In this section; the results are discussed in terms of creep and elastic properties obtained by microindentation for the ACC:V 1:3 composition conditioned and tested under 33\%; 54\% and 93\% RH.

For what concerns the creep properties; the best-fit parameters obtained for Eq. 15 are represented on Figure 11 as a function of the relative humidity. At a glance; Figure 11 shows that the characteristic time needed to reach logarithmic kinetics varied greatly with the relative humidity. From about 2 seconds for the samples conditioned at $33 \%$ and $54 \% \mathrm{RH}$; it raises up to 12 seconds for the sample in moisture equilibrium with a 94\% relative humidity atmosphere. That means an increase by factor 6 with increasing RH. On the other hand; the contact creep modulus; $C i$; drops dramatically from about $45 \mathrm{GPa}$ at $33 \% \mathrm{RH}$ to $\sim 5 \mathrm{GPa}$ at $54 \%$ $\mathrm{RH}$ and to $\sim 0.1 \mathrm{GPa}$ under $93 \% \mathrm{RH}$. Thus; the former drop corresponds to a factor 9 while the latter is over a factor 50. The latter drop may seem extremely large but even larger breakdowns have been reported previously for other pastes. For instance; a drop by a factor 100 was reported for the contact creep modulus; $\mathrm{Ci}$; of gypsum plaster when moving from medium $\mathrm{RH}(\sim 50 \%)$ towards water-saturated conditions $(\sim 100 \%)$ [32]. Thus; the amplitude of the creep rate increases exponentially with the $\mathrm{RH}$ for $\mathrm{CaCO}_{3}$ cements; as it does for other binders. 


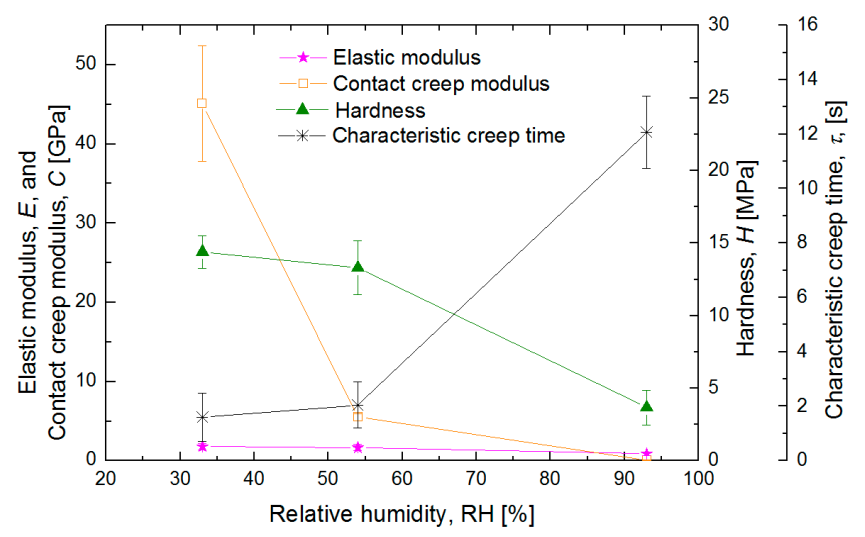

Figure 11. Young's modulus; E; Contact creep modulus; C; Indentation hardness; H; and Characteristic creep time; $\tau$; calculated from microindentation tests performed on 28-day-old ACC:V 1:3 CaCO $\mathrm{C}_{3}$ cement specimens as function of the conditioning and testing relative humidity (RH).

The elastic modulus; $E$; and hardness; $H$; calculated - as detailed in Section 2.3.3 -; from the short-holdingphase $\mu$-indentation tests (assuming a Poisson's ratio $v=0.20$ ) are also included on Figure 11 as function of the relative humidity. As can be observed; both parameters decrease with the RH but not as dramatically as the contact creep modulus; $\mathrm{Ci}$. Indeed; both the elastic modulus; $E$; and the hardness; $H$; just show a decrease of about $8-9 \%$ of their original value when the $\mathrm{RH}$ rises from $33 \%$ to $54 \%$; whereas from $54 \%$ to $93 \%$ RH the breakdown is in the order of $50-60 \%$ of their reference values. Moreover; although just three $\mathrm{RH}$ values were evaluated; the results suggest that the contact creep modulus; $\mathrm{Ci}$; of $\mathrm{CaCO}_{3}$ cements decreases exponentially in function of relative humidity. However; a critical relative humidity point has been reported previously for both $\mathrm{C}_{3} \mathrm{~S}$ and C-S-H compacts [32]; above which the contact creep modulus; $\mathrm{C} i$; stays constant. For $\mathrm{C}_{3} \mathrm{~S}$ samples the critical relative humidity value lies somewhere between $\mathrm{RH}=54 \%$ and $\mathrm{RH}=75 \%$; whereas between $75 \%$ and $94 \%$ for C-S-H compacts. On the contrary; for $\mathrm{CaCO}_{3}$ cements the contact creep modulus; $\mathrm{C} i$; continues decreasing up to $\mathrm{RH}=94 \%$.

Figure 12 includes a comparative study between the elastic modulus; $E$; and hardness; $H$; with the contact creep modulus; $\mathrm{Ci}$. In contrast with the effect of microstructure; which makes both the elastic modulus; $E$; and hardness; $H$; to follow a linear relationship with the contact creep modulus; $\mathrm{C} i$; the effect of the relative humidity makes these relationship to be exponential. More specifically; for the two moduli; all data points yields into the following equation: $E i=E_{0} \cdot \exp (-C i / \tau)$ GPa with a relation rate; $\tau=5.71$; whereas the comparison between the hardness; $\mathrm{H}$; and the contact creep modulus; $\mathrm{Ci}$; follows: $\mathrm{Hi}=\mathrm{H}_{0} \cdot \exp (-\mathrm{Ci} / \tau)$ GPa with a relation rate; $\tau=8.59$. Thus; the relative humidity influences the contact creep modulus; $C i$; on a greater manner than the elastic modulus; $E$; and the hardness; $H$. 


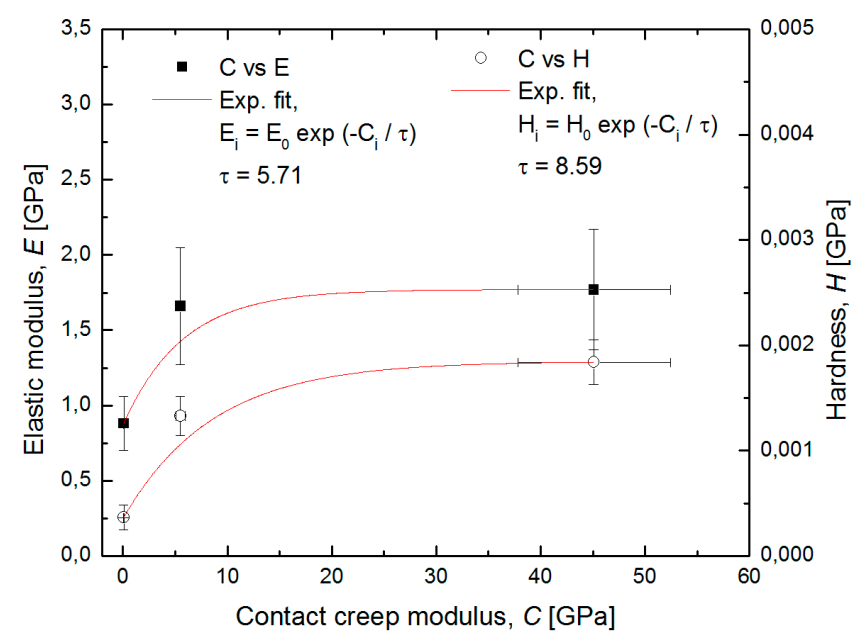

Figure 12. Contact creep modulus; $C i$; versus elastic modulus; $E$; and hardness; $H$; for $A C C: V 1: 3 \mathrm{CaCO}_{3}$ cement specimens conditioned and tested under 33\%; $54 \%$ and $93 \%$ RH.

As commented previously; the porosity of all $\mathrm{CaCO}_{3}$ cements compositions here tested is very similar $(\phi=$ $39 \%$ ). When a porous material dries; the larger pores desaturates firstly followed by the smallest ones. Indeed; the largest pore entry radius; $r_{p e}$; i.e.; the largest pore which remains saturated for a porous material in moisture equilibrium with a given relative humidity; can be calculated by applying the Kelvin-Laplace law for drying with the following equation [62]:

$$
r_{p e}=\frac{2 \gamma_{g l} \cos \theta}{R T / V_{m ; H_{2} O} \ln R H}
$$

where $\gamma_{\mathrm{gl}}$ is the air-water interface energy; $\mathrm{T}$ is the temperature; $\mathrm{R}$ is the ideal gas constant; $\theta$ is the wetting angle; $\mathrm{V}_{\mathrm{m} ; \mathrm{H} 2 \mathrm{O}}$ is the molar volume of water and $\mathrm{RH}$ is the relative humidity at a given temperature. At a temperature $\mathrm{T}=295 \mathrm{~K}$; with $\gamma_{\mathrm{gl}}=73 \mathrm{~mJ} / \mathrm{m}^{2} ; \theta=0 ; \mathrm{R}=8.31 \mathrm{~J} /(\mathrm{mol} \cdot \mathrm{K})$ and $\mathrm{V}_{\mathrm{m} ; \mathrm{H} 2 \mathrm{O}}=18 \mathrm{~cm}^{3} / \mathrm{mol}$; the relation between the relative humidity within the sample and the largest pore entry radius is presented in Figure 13. As can be observed; the lower the relative humidity is; the smaller this radius is.

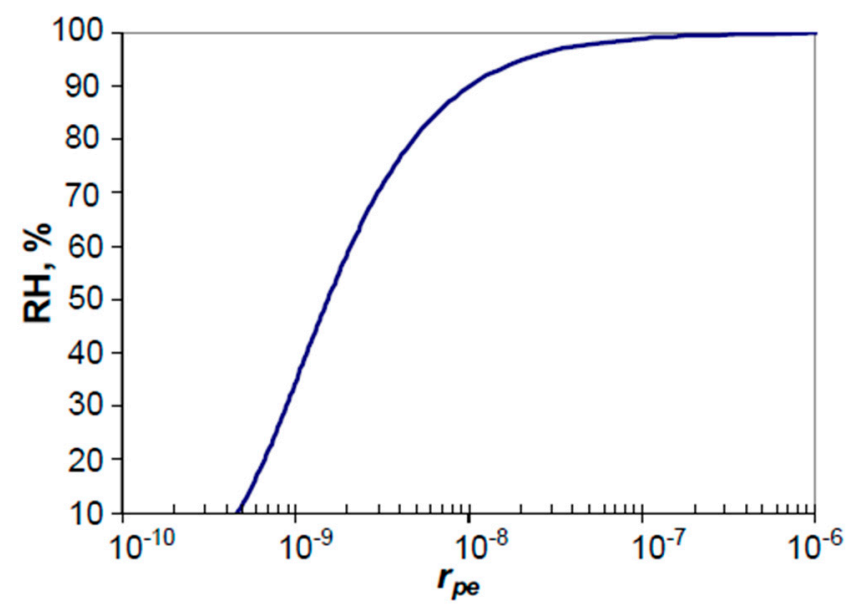

Figure 13. Largest radius $r_{p e}$ of pores remaining saturated at various relative humidity. 
By applying Eq. 16 for the RH values here studied; the radius of the largest pores remaining saturated under each situation; $\mathrm{r}_{\mathrm{pe}}$; can be estimated. Values of $\sim 1 \mathrm{~nm} ; \sim 2 \mathrm{~nm}$ and $\sim 10 \mathrm{~nm}$ are obtained for $33 \%$; $54 \%$ and 93\% RH; respectively. Thus; from this analysis it seems that water in pores with an entry radius smaller than those values - at each specific condition - is linked to the long-term basic creep properties of $\mathrm{CaCO}_{3}$ cements. In addition; a contribution from the water activity by itself cannot be discarded for this kind of material. The presence of more intergranular water might enhance the local dissolution of calcite and thus increase the amplitude of creep strains; in agreement with the pressure solution theory introduced on the previous section. Moreover; other mechanisms may be activated by the presence of fluids within the calcite network as the aforementioned frictional grain boundary sliding mechanism. Under this scenario; calcite dissolution can remove asperities and will reduce the friction between grains; making the creep amplitude to rise.

While the contact creep modulus; $C i$; of gypsum plaster; calcium carbonate cements and calcium hydroxide compacts increases by a factor of 100; 50 and 12 respectively; from water-saturated condition ( $95 \%)$ to medium relative humidity $(\sim 50 \%)$; this increment is only by factor 2 for $\mathrm{C}_{3} \mathrm{~S}$ and $\mathrm{C}-\mathrm{S}-\mathrm{H}$ compacts. Therefore; the creep properties of $\mathrm{CaCO}_{3}$ cements; in line with other crystalline binders; appear to be more sensitive to the relative humidity than other materials which contain amorphous phases like C-S-H.

\section{Conclusions}

In this paper; we have studied the compressive strength; the elasticity and the long-term creep properties of calcium carbonate cements with diverse microstructures; conditioned at several relative humidity. The results show that a larger starting amount of vaterite; $X_{V}$; within the mixture design derives on more elastic and resistant specimens due to the larger overall bridging area within the newly formed calcite crystals.

The micro-indentation results show that creep is logarithmic with respect to time; and hence the contact creep modulus; $\mathrm{C} i$; and the characteristic creep time; $\tau$; could be extracted from each test. For a given relative humidity; the amplitude of creep strain decreases with increasing initial amount of vaterite; making the contact creep modulus; $C i$; to rise on a linear manner with the elastic modulus; $E$; and hardness; $H$; of the specimens. The differences among their properties must be due to their particular microstructure and the joint's strength among the $\mathrm{CaCO}_{3}$ grains after the setting reaction. Moreover; the most probable creep mechanisms seem to be a combination of microcraking in the early stages and dissolution and reprecipitation of calcite in the long-term (also known as pressure solution theory).

On the other hand; for a given composition; the amplitude of creep grows with the increase of relative humidity; inducing the contact creep modulus; $\mathrm{C} i$; the elastic modulus; $E$; and hardness; $H$; of the samples to decrease. The presence of water in pores with an entry radius smaller than $1 \mathrm{~nm}$; $2 \mathrm{~nm}$ or $10 \mathrm{~nm}$ under $33 \%$; $54 \%$ and $93 \%$ RH conditions respectively; may enhance the local dissolution of calcite and explain the raise of the creep amplitude. This hypothesis is also in agreement with the pressure solution theory and support the fact that crystalline binders; such as our calcium carbonate cements; are more sensitive to the relative humidity than others which contain amorphous phases like C-S-H. 
Furthermore; the results suggest that the mechanical properties of calcium carbonate cements are enforced when reducing the fraction of ACC in the mixture design. However; their mechanical properties become more sensitive to relative humidity; especially creep. These results are in accordance with the findings for C-S-H (amorphous) and gypsum (crystalline).

\section{Acknowledgments}

This project has received funding from the European Union Horizon 2020 research and innovation program under the Marie Skłodowska-Curie grant agreement no. 642976-NanoHeal Project. The results of this paper reflect only the author's view and the Commission is not responsible for any use that may be made of the information it contains. J.R.-S.- would like to express his thanks to Francois Renard (University of Oslo \& Universite Grenoble-Alpes) for making possible the compressive strength tests; to Martin Mosquet and Quoc Huy Vu (both from Lafarge Centre of Research) for their help to upgrade the micro-indenter and for various supports during the performance of the micro-indentation creep experiments.

\section{References}

[1] E.M. Gartner; D.E. Macphee; A physico-chemical basis for novel cementitious binders; Cem. Concr. Res. 41 (2011) 736-749. doi:10.1016/j.cemconres.2011.03.006.

[2] J.L. Provis; J.S.J. van Deventer; Alkali Activated Materials; Springer; 2014.

[3] T. Zhang; C.R. Cheeseman; L.J. Vandeperre; Development of low pH cement systems forming magnesium silicate hydrate (M-S-H); Cem. Concr. Res. 41 (2011) 439-442. doi:10.1016/j.cemconres.2011.01.016.

[4] H. Justnes; Alternative Low-CO2 "Green" Clinkering Processes; Rev. Mineral. Geochemistry. 74 (2012) 83-99. doi:10.2138/rmg.2012.74.2.

[5] P. Cailleau; Etude petrologique experimentale de la cimentation calcitique et aragonitique; $\mathrm{PhD}$ Thesis; Universite de Bordeaux 3; 1982.

[6] N. Molenaar; A.A.M. Venmans; Calcium carbonate cementation of sand: A method for producing artificially cemented samples for geotechnical testing and a comparison with natural cementation processes; Eng. Geol. 35 (1993) 103-122. doi:http://dx.doi.org/10.1016/0013-7952(93)90073-L.

[7] M. a. Ismail; H. a. Joer; M.F. Randolph; A. Meritt; Cementation of porous materials using calcite; Géotechnique. 52 (2002) 313-324. doi:10.1680/geot.2002.52.5.313.

[8] M.-L. Fontaine; C. Combes; T. Sillam; G. Dechambre; C. Rey; New Calcium Carbonate-Based Cements for Bone Reconstruction; Key Eng. Mater. 284-286 (2005) 105-108. doi:10.4028/www.scientific.net/KEM.284-286.105.

[9] C. Combes; B. Miao; R. Bareille; C. Rey; Preparation; physical-chemical characterisation and cytocompatibility of calcium carbonate cements; Biomaterials. 27 (2006) 1945-1954. doi:10.1016/j.biomaterials.2005.09.026.

[10] P. Phillips; The slow stretch in indiarubber; glass; and metal wires when subjected to a constant pull; Philos. Mag. J. Sci. 9 (1905) 513-531.

[11] E.D.C. Andrade; On the viscous flowin metals; and allied phenomena; Proc. R. Soc. 84 (1910) 1-12.

[12] Z.P. Bažant; M.H. Hubler; Q. Yu; Pervasiveness of excessive segmental bridge deflections: Wake-up call for creep; ACI Struct. J. 108 (2011) 766-774. doi:10.1017/CBO9781107415324.004.

[13] R.I. Gilbert; Time effects in concrete structures; Amsterdam; 1988.

[14] D.T. Griggs; Deformation of rocks under high confining pressures: I. Experiments at room temperature; J. Geol. 44 (1936) 541-577.

[15] N.L. Carter; S.H. Kirby; Transient creep and semibrittle behavior of crystalline rocks; Pure Appl. Geophys. 116 (1978) 807-839.

[16] M.F. Ashby; C.G. Sammis; The damage mechanics of brittle solids in compression; Pure Appl. Geophys. PAGEOPH. 133 (1990) 489-521. doi:10.1007/BF00878002. 
[17] N. Brantut; P. Baud; M.J. Heap; P.G. Meredith; Micromechanics of brittle creep in rocks; J. Geophys. Res. Solid Earth. 117 (2012) 1-12. doi:10.1029/2012JB009299.

[18] D. Keszthelyi; D.K. Dysthe; B. Jamtveit; First principles model of carbonate compaction creep; J. OfGeophysical Res. Solid Earth. 121 (2016) 3348-3365. doi:10.1002/2015JB012481.Rocks.

[19] G. Pickett; The effect of change in moisture-content on the creep of concrete under a sustained load; ACI J. Proc. 38 (1942).

[20] B.T. Tamtsia; J.J. Beaudoin; Basic creep of hardened cement paste. A re-examination of the role of water; Cem. Concr. Res. 30 (2000) 1465-1475. doi:10.1016/S0008-8846(00)00279-9.

[21] F.G. Thomas; Creep of concrete under load; Int. Assoc. Test. Mater. 4 (1937) 292-294.

[22] W. Ruetz; A hypothesis for the creep of hardened cement paste and the influence of simultaneous shrinkage; Proc. Struct. Concr. Its Behav. under Load. (1968) 365-387.

[23] C.G. Lynam; Growth and movement in Portland cement concrete; London; 1934.

[24] B. Bissonnette; M. Pigeon; Le comportement viscoélastique du béton en traction et la compatibilité déformationnelle des réparations; Mater. Struct. 33 (2000) 108-118. doi:10.1007/BF02484165.

[25] Z.P. Bažant; A.B. Hauggaard; S. Baweja; F.-J. Ulm; Microprestress-Solidification Theory for Concrete Creep. I: Aging and Drying Effects; J. Eng. Mech. 123 (1997) 1188-1194. doi:10.1061/(ASCE)0733-9399(1997)123:11(1188).

[26] P. Acker; F.J. Ulm; Creep and shrinkage of concrete: Physical origins and practical measurements; Nucl. Eng. Des. 203 (2001) 143-158. doi:10.1016/S0029-5493(00)00304-6.

[27] Q. Zhang; R. Le Roy; M. Vandamme; B. Zuber; Long-term creep properties of cementitious materials: Comparing microindentation testing with macroscopic uniaxial compressive testing; Cem. Concr. Res. 58 (2014) 89-98. doi:10.1016/j.cemconres.2014.01.004.

[28] J. Rodríguez-Sánchez; T. Liberto; C. Barentin; D.K. Dysthe; Mechanisms of phase transformation and creating mechanical strength in a sustainable calcium carbonate cement; Preprints. (2018). doi:doi: 10.20944/preprints201810.0526.v1.

[29] T. Ogino; T. Suzuki; K. Sawada; The formation and transformation mechanism of calcium carbonate in water; Geochim. Cosmochim. Acta. 51 (1987) 2757-2767. doi:10.1016/0016-7037(87)90155-4.

[30] G.L. Squires; Practical physics; Cambridge university press; 2001.

[31] L. Greenspan; Humidity fixed points of binary saturated aqueous solutions; J. Res. Natl. Bur. Stand. Sect. A Phys. Chem. 81A (1977) 89-96. doi:10.6028/jres.081A.011.

[32] Q. Zhang; PhD thesis; Creep properties of cementitious materials: effect of water and microstructure. An approach by microindentation; _Ecole des Ponts ParisTech; 2014.

[33] ASTM Standard E2546-7.; Standard Practice for Instrumented Indentation Testing; ASTM International; West Conshohocken; 2007.

[34] S.R. Kalidindi; a. Abusafieh; E. El-Danaf; Accurate characterization of machine compliance for simple compression testing; Exp. Mech. 37 (1997) 210-215. doi:10.1007/BF02317861.

[35] Y. Lee; S.T. Yi; M.S. Kim; J.K. Kim; Evaluation of a basic creep model with respect to autogenous shrinkage; Cem. Concr. Res. 36 (2006) 1268-1278. doi:10.1016/j.cemconres.2006.02.011.

[36] L. Østergaard; D.A. Lange; S.A. Altoubat; H. Stang; Tensile basic creep of early-age concrete under constant load; Cem. Concr. Res. 31 (2001) 1895-1899. doi:10.1016/S0008-8846(01)00691-3.

[37] G. Schutter; L. Taerwe; Fictitious degree of hydration method for the basic creep of early age concrete; Mater. Struct. 33 (2000) 370-380. doi:10.1007/BF02479646.

[38] L.A. Galin; H. Moss; N.I. Sneddon; Contact problems in the theory of elasticity; Ft. Belvoir Defense Technical Information Center; 1961.

[39] S.I. Bulychev; V.P.Alekhin; M.K. Shorshorov; A.P. Ternovskij; G.D. Shnyrev; Determination of young's modulus according to indentation diagram; Zavod. Lab. 41 (1975) 1137-1140.

[40] W.C. Oliver; G.M. Pharr; An improved technique for determining hardness and elastic modulus using load and displacement sensing indentation experiments; J. Mater. Res. 7 (1992) 1564-1583. doi:https://doi.org/10.1557/JMR.1992.1564.

[41] I.N. Sneddon; The relation between load and penetration in the axisymmetric boussinesq problem for a punch of arbitrary profile; Int. J. Eng. Sci. 3 (1965) 47-57. doi:10.1016/0020-7225(65)90019-4.

[42] M. Vandamme; C.A. Tweedie; G. Constantinides; F.J. Ulm; K.J. Van Vliet; Quantifying plasticityindependent creep compliance and relaxation of viscoelastoplastic materials under contact loading; J. Mater. Res. 27 (2012) 302-312. doi:10.1557/jmr.2011.302. 
[43] C. Combes; S. Tadier; H. Galliard; S. Girod-Fullana; C. Charvillat; C. Rey; R. Auzely-Velty; N. El Kissi; Rheological properties of calcium carbonate self-setting injectable paste; Acta Biomater. 6 (2010) 920-927. doi:10.1016/j.actbio.2009.08.032.

[44] B.B. Schroeder; D.D. Harris; S.T. Smith; D.O. Lignell; Theoretical framework for multiplepolymorph particle precipitation in highly supersaturated systems; Cryst. Growth Des. 14 (2014) 1756-1770. doi:10.1021/cg401892b.

[45] P. Baud; U. Exner; M. Lommatzsch; T. Reuschlé; T. Wong; Mechanical behavior; failure mode and transport properties in a porous carbonate; J. Geophys. Res. Solid Earth. (2017) 1-25. doi:10.1002/2017JB014060.

[46] K. Ishikawa; N. Koga; K. Tsuru; I. Takahashi; Fabrication of interconnected porous calcite by bridging calcite granules with dicalcium phosphate dihydrate and their histological evaluation; J. Biomed. Mater. Res. - Part A. 104 (2016) 652-658. doi:10.1002/jbm.a.35604.

[47] M. Vandamme; F.J. Ulm; Nanoindentation investigation of creep properties of calcium silicate hydrates; Cem. Concr. Res. 52 (2013) 38-52. doi:10.1016/j.cemconres.2013.05.006.

[48] M. Vandamme; F.-J. Ulm; Nanogranular origin of concrete creep; Proc. Natl. Acad. Sci. 106 (2009) 10552-10557. doi:10.1073/pnas.0901033106.

[49] A. Committee; Prediction of creep; shrinkage; and temperature effects in concrete structures; manual of concrete practice.; in: American Concrete Institute; Detroit; MI; 1999.

[50] J.T. Fredrich; B. Evans; Micromechanics of the brittle to plastic transition in carrara marble; J. Geophys. Res. 94 (1989) 4129-4145. doi:10.1029/JB094iB04p04129.

[51] A.M.H. Pluymakers; C.J. Peach; C.J. Spiers; Diagenetic compaction experiments on simulated anhydrite fault gouge under static conditions; J. Geophys. Res. Solid Earth. 119 (2014) 4123-4148. doi:10.1002/2014JB011073.Received.

[52] Z.P. Bazant; Current status and advances in the theory of creep and interaction with fracture; in: Z.P. Bazant; I. Carol (Eds.); Creep Shrinkage Concr.; RILEM Proceedings; CHAPMAN \& HALL; Barcelona; 1993: pp. 291-291.

[53] P.F. Williams; L.B. Goodwin; S. Ralser; Ductile deformation processes; in: P.L. Hancock (Ed.); Cont. Deform.; Pergamon Press; Oxford; 1994: p. 27.

[54] R. Raj; Creep in polycrystalline aggregates by matter transport through a liquid phase; J. Geophys. Res. 87 (1982) 4731-4739.

[55] E.H. Rutter; Pressure solution in nature; theory and experiment; J. Geol. Soc. London. 140 (1983) 725-740. doi:10.1144/gsjgs.140.5.0725.

[56] P.K. Weyl; Pressure solution and the force of crystallization: a phenomenological theory; J. Geophys. Res. 64 (1959) 2001-2025. doi:10.1029/JZ064i011p02001.

[57] R.L. Coble; A Model for Boundary Diffusion Controlled Creep in Polycrystalline Materials; J. Appl. Phys. 34 (1963) 1679-1682. doi:10.1063/1.1702656.

[58] F. Renard; P. Ortoleva; Water films at grain-grain contacts: Debye-Hückel; osmotic model of stress; salinity; and mineralogy dependence; Geochim. Cosmochim. Acta. 61 (1997) 1963-1970. doi:10.1016/S0016-7037(97)00036-7.

[59] D. Croizé; F. Renard; K. Bjørlykke; D.K. Dysthe; Experimental calcite dissolution under stress: Evolution of grain contact microstructure during pressure solution creep; J. Geophys. Res. Solid Earth. 115 (2010) 1-15. doi:10.1029/2010JB000869.

[60] S. Zubtsov; F. Renard; J.-P. Gratier; D.K. Dysthe; V. Traskine; Single-contact pressure solution creep on calcite monocrystals; Geol. Soc. London; Spec. Publ. 243 (2005) 81-95. doi:10.1144/GSL.SP.2005.243.01.08.

[61] E.A. Pachon-Rodriguez; E. Guillon; G. Houvenaghel; J. Colombani; Pressure solution as origin of the humid creep of a mineral material; Phys. Rev. E - Stat. Nonlinear; Soft Matter Phys. 84 (2011) 1-5. doi:10.1103/PhysRevE.84.066121.

[62] O. Coussy; Poromechanics; John Wiley \& Sons; Ltd; 2004. doi:10.1002/0470092718. 